\title{
Active Learning for Active Citizenship: participatory approaches to evaluating a programme to promote citizen participation in England
}

\section{Introduction}

Just as the notion of participatory approaches has been subjected to questioning and criticism, so has the more specific notion of participatory approaches to monitoring and evaluation. There are parallel possibilities of tokenism and even of manipulation, here, just as there are parallels around the need for more critical reflection and dialogue. Even if not actually manipulative, participatory evaluation can involve little more than the occasional use of particular techniques from a participatory toolkit.

This article draws upon our experiences of evaluating a participatory programme to promote active citizenship in England, starting from our shared commitment to achieve more than this. Building upon principles and experiences of best practice, the aim was to use participatory principles 'in order to democratise social change' (Cousins and Whitmore, 1998.7), addressing the challenges of putting participatory principles into practice right from the outset, through to the completion of the final report.

We begin by summarising key arguments from previous debates. This sets the context for the discussion of our case study, as evaluators of this particular programme. Finally, we conclude by reflecting upon our experiences of working with some of the tensions inherent in the processes associated with participatory monitoring and evaluation, identifying similarities with as well as differences from Kate Newman's conclusions, on the basis of her experiences in the global South.

\section{Participatory monitoring and evaluation: more contested concepts?}

In summary, critiques of participation as the 'new tyranny?' have included discussion of the ways in which participative approaches to community development may be used to distract attention away from wider structural factors, including inbuilt imbalances of power within localities as well as beyond them. 'Participation' can become little more than window dressing. Similar criticisms may be applied to participatory approaches to monitoring and evaluation. Local people may tell potential donors what they think they want to hear, for example, as a strategy to obtain desperately needed resources, whether or not donors' priorities closely match their own in practice - working on the principle that 'beggars can't be choosers', effectively, whatever the rhetoric to the contrary. Participative monitoring and evaluation processes may also make unrealistic demands on people's time. And, in addition, it has been argued, participative tools may become fetishised, to the detriment of other approaches and knowledges, even where these may be needed to respond to formal and informal bureaucratic requirements (Cooke and Kothari, 2001, Mosse, 2001). As an earlier Policy Briefing from the Participation Team at the Institute of Development Studies had already pointed out, participatory monitoring and evaluation 'is not just a matter of using participatory techniques within a conventional monitoring and evaluation setting. It is about radically 
rethinking who initiates and undertakes the process, and who learns or benefits from the findings' (IDS. 1998. 1). These reflections provided a framework for our thinking as we attempted to develop our evaluation strategy from the earlier stages of the programme, aiming to use participative tools along with other methods, to meet external requirements whilst promoting shared learning, on a continuing basis, rather than collecting 'grateful testimonials' to present to funders.

Participative tools and toolkits do have key roles to play, however. There are parallels here with the audit tools have been developed in Britain to provide comprehensive, regular, comparative, externally validated and transparent ways of facilitating learning and dialogue, rather than simply undertaking traditional evaluations, at the end of a particular programme (Burns and Taylor, 2000). Such tools can be used for selfassessment, although there are clearly benefits to be gained from involving an outside facilitator too, especially if the tools are to be used for external validation. As the authors of the combined audit and benchmarking tools that were road-tested for use in monitoring and evaluating community involvement in regeneration reflected, however, on their own, even these tools were not enough, (Burns et al, 2004).

In a companion volume, they presented their findings and their conclusions about the process of using these assessment frameworks. Roadtesting provided insights, they pointed out, into the general state of participation policy and practice overall, (illustrating continuing problems of tokenistic consultation, as those with more powerful voices found ways of holding onto power, re-inforcing the marginalisation of those less powerful and those already feeling marginalised). The authors emphasised the importance of skilled facilitation and continuing feedback, in order to engage constructively on such issues, using a range of research methods to meet the varying information needs of the different stakeholders involved (Burns et al, 2004). Relatively objective data (such as the findings of surveys, for instance) had their place, they argued, even within this type of research, alongside the findings from more participatory methodologies. Overall then, this was about building relationships of trust, whilst maintaining sufficient distance to be able to offer constructive criticism, on a continuing basis, as critical friends.

\section{Active Learning for Active Citizenship (ALAC): participatory monitoring and evaluation for a government sponsored programme}

Active Learning for Active Citizenship (ALAC) was set up in 2004, as a community education programme to promote participation, based upon community development principles. Although this was a government sponsored programme, it was firmly located within the voluntary and community sectors, building upon networks of organisations and agencies with a track record of good practice. These networks were based around seven hubs, within different English regions, working in partnership with community education providers in universities and the Workers Education Association (a long established voluntary sector provider of workplace and community-based learning). Between them the seven hubs addressed a wide range of learning requirements, including those of women, ethnic minority communities, migrant agricultural workers, refugees and asylum seekers, faith communities, people with disabilities and carers - as 
well as addressing the requirements of long established communities of tenants and residents. So these were very flexible programmes of learning, varying from mentoring, one off workshops and visits through to more structured programmes of learning over a three month period or more.

Whilst the forms and levels of learning programmes were very diverse, to meet these differing requirements, however, they were firmly based upon a set of common principles. Drawing upon the work of Paulo Freire, the learning was driven by people's own priorities and needs, respecting and building upon people's existing knowledge and skills, rather than starting from a 'deficit' model of individuals and communities as being in some way in need of 'treatment'. (Woodward, 2004). There was an emphasis upon experiential learning, both individually and collectively within the group, through critical reflection and dialogue and through collective action, based upon shared principles of equalities, respect for diversity and co-operation, social solidarity and social justice. ALAC was to promote active citizenship, participation and empowerment through learning processes that were themselves participatory and empowering.

Although ALAC was modestly resourced and time limited over a two year period, the results fully demonstrated its value as a community development based approach. The Evaluation Report (Mayo and Rooke, 2006) summarises the outcomes, in terms of the numbers of participants (nearly 1,400) and the learning journeys travelled, both individually and collectively in groups. Individuals and groups became more active and more effective in grassroots community activities and within governance structures, as well as impacting on the provision of health and welfare services more effectively. Most importantly, there was also evidence of reduced tensions between different communities in particular areas, as established communities strengthened challenges to racism, gaining deeper understanding of the issues affecting newcomers such as refugees and asylum seekers. A Refugees Charter was launched with widespread support in one area, for example.

This article focuses upon the monitoring and evaluation processes, however, rather than the outcomes, per se. In accordance with ALAC's participatory approach, overall, monitoring and evaluation were to be participatory processes too. The aim was to facilitate critically reflective self-evaluations, sharing the learning within and between the hubs, on an on-going basis, informing the policy makers along the way as well via the programme's conclusions from the final report. We reported regularly to a Steering Committee of representatives from concerned government departments and other stakeholders together with people with relevant expertise from the voluntary and community sectors.

In practice, the evaluation involved a series of visits to the hubs together with a series of workshops, seminars and conferences, bringing community participants together with learning providers and with policy makers to reflect upon their experiences and to share reflections on the lessons for future policies and practice. ${ }^{1}$ Together with the hubs we devised the strategy and the 'Evaluation Framework', the paper that set out the key

\footnotetext{
${ }^{1}$ The Learning Framework (ref) provides a continually updated web based account of these.
} 
questions to be addressed in assessing outcomes, going beyond the numbers game of the formally agreed targets to explore the processes of how these outcomes were being achieved, using what methods and approaches, with what lessons for the future - what were the challenges and what would need to change, to take active learning for active citizenship forward, locally, nationally and internationally? This was the framework within which participative tools were applied, tools such as the use of video, and the use of participative exercises to stimulate collective reflection. And, as the following section will explain in more detail, more traditional methods and approaches also had their place.

This was an extremely rewarding experience, overall. The remit provided the space to develop participatory approaches to monitoring and evaluation, sharing the learning throughout the process. The government funders ${ }^{2}$ genuinely respected this, although periodic requests for hard outputs emerged too - unsurprisingly given the target culture that predominated within government at the time. And the hubs gave generously of their time. As the final report commented, the evaluation process did become a valuable part of the learning, overall. We particularly appreciated the ways in which ALAC participants shared in these processes of reflection and actively contributed to the final evaluation workshop.

\section{Challenges in practice}

Whilst this was such a positive experience for us, as evaluators committed to working in participative ways, it would be misleading to suggest that the process was without its challenges. It wasn't. The first task was to build relationships of trust with the hubs, as the basis for facilitating shared learning, as critical friends. And the hubs needed to check us out. Were we serious about this commitment to working in participative ways and would monitoring and evaluation processes actually add value to the hubs' work? Ideally there would have been more time for this phase - relationship building doesn't just happen at the first meeting, normally - but there was less than eighteen months within which to develop the strategy and produce the final report. The hubs demonstrated real generosity in accepting the process as rapidly as they did.

Time was a continuing challenge though. The hubs were effectively working against the clock. And participative monitoring and evaluation takes time. A balance needed to be negotiated here - and renegotiated to take account of changing pressures as the hubs developed their work.

There were challenges too, in meeting the requirements of the different stakeholders, including the policy makers and other potential funders, for the future. Whilst there was genuine acceptance of the importance of participative approaches, there were pressures for more traditional indicators of outcomes too. However supportive the champions in government, they needed facts and figures - 'hard evidence' if they were to convince politicians of the value of public spending on active learning for active citizenship. So we needed to collect data on outcomes, facts and figures on the numbers of participants, for

\footnotetext{
${ }^{2}$ From the outset ALAC was based in the Civil Renewal Unit in the Home Office and was subsequently relocated to the newly formed department of Communities and Local Government in 2006.
} 
instance, including the numbers that obtained formal accreditation and/ or progressed in other ways into further education or training or into enhanced employment opportunities. And we needed to collect hard information on outcomes in terms of the impact on community engagement, how many participants became more active and what impact this activity was having in terms of improved service provision and in terms of strengthened community cohesion - reduced conflict within and between communities and increased solidarity between established communities and newer arrivals, for example. Given the diversity of learning across the hubs, there were considerable challenges here, if this 'hard' information was to be presented in comparable ways. The final report attempted to strike a balance here too, including as much comparable data as we could reasonably compile in the time available, whilst giving prominence to the more qualitative findings based upon the more participatory processes.

We concluded, overall, that monitoring and evaluating individual learning outcomes posed the least of our problems. The hubs were well used to detailed recording procedures - standard in community education practice in Britain, these days - working with participants to track their aims and achievements, and to follow participants up, subsequently. Written records were supplemented with the use of other forms of recording such as the use of photographs (including photographs of workshops using participative tools) and video tapes recording events such as the West Midlands women's visit to Brussels to learn more about how to engage in advocacy to impact upon policy making at the European Level.

It was the wider impacts upon communities and public policy that posed the greatest challenges within our limited timeframe. The ripple effects of the production of the Refugees' Charter may take more than months to spread, for example, and so may the ripple effects of enabling community activists to gain the knowledge and skills to research their own needs, in their communities. The following example illustrates some of the potential uses of participative tools to draw out these more qualitative aspects, tracking the links between participants' experiences as individuals and within their communities, locally and beyond, nationally and even internationally as they explored issues such as racism against newly arrived refugees and asylum seekers .

\section{The Participative Evaluation Workshop in Sheffield}

An evaluation workshop which was held in Sheffield invited the ALAC hub cocoordinators and participants to reflect on the multiple impacts of their participation in ALAC. This session was an opportunity to 'road test' the ALAC evaluation framework, and is one example of how participative methods were used to set out a robust case which demonstrated the strength of ALAC for funders whilst simultaneously doing justice to the varied and complex interrelated outcomes which have emerged as a result of the flexible and participative nature of the programme. This session invited participants to come together for a one day event in order to share their perspectives on ALAC's, impact. The aim was to track the impact on individuals and their families, and to track the wider ripple effects on service planning, service delivery and policy. This session was both an opportunity to reflect on 'what counts as an impact' and 'how to evidence 
an impact'. , exploring the ways that individual participants had gone on to have an impact as active citizens locally, regionally, nationally, globally. One of the themes was the ways that services had improved and how social cohesion (or solidarity) had increased. These were some of the most problematic aspects of the evaluation: how to attribute impacts to the programme and how to evaluate increased social solidarity and community cohesion. Through group discussion and reflection, however, participants did find succeed in sharing the ways in which participation had impacted on their lives and the lives of those around them. As one participant reflected

The first residential was a big concern for me. (It was) the first time I had ever left my family overnight and in a strange place on my own. I had to do a lot of preparation - a lot of practical organising; food, school clothes, washing etc. I then threw myself into it and thought 'if the worst comes to the worst I can always leave ands go home!'! But it was great - and it changed our family relationships in ways I didn't think about (before)- my husband spent time with the kids on his own, took them out for a meal - never done that before - changed his relationship the kids - closer. They can't wait for me to go on the next one and go to Brussels for 2 nights. They keep reminding me to sort out the passport and all that'.

Figure 1 is a reproduction of one of these maps of influence that were drawn by participants in the workshop, tracing the impact from the self out to global impacts. These were opportunities to share stories. So, for example, on participant explained how she had been frustrated with the poor quality of life in her neighborhood, then how she had set up a tenants association, learnt what local and regional agencies should be doing, and begun to understand how local structures of power were operating. This involved going to council meetings and not feeling listened to - and learinng from these experiences. Through making her approach more strategic, as a result, she went on to bring about more significant improvements to her neighborhood, going on to represent her area on the Community Empowerment Network. One challenge that required a more strategic approach was getting policing improved on her estate, for example, by by-passing blocks that she had been encountering at the more local 'beat' level. Another participant reflected on how she had become an independent representative on her local Care Panel and how this had resulted in improving ongoing support for foster carers. She then discussed her experiences of volunteering at a new one-stop shop children's centre where she became involved in citizenship learning, providing further illustrations of the processes of learning through active citizenship - and learning about active citizenship, via ALAC and subsequently.

In this session it emerged that much of the learning, and the impact of this learning, within and between communities had taken place through facilitated workshop. But at other times it had been the result of activities that had cascaded out from ALAC. Communities had come together around common concerns, identifying their issues and training needs, sharing information between groups and communities, increasing dialogue between communities and raising community awareness about local services and how to access them. The session pinpointed how participants had become more 
organised and involved in structured grassroots community activity and local networks as well as governance structures, participating effectively in new forums and partnerships that impact on communities, within communities and between communities. Through the 'mapping influence' exercise it became clear then that groups and communities had indeed been taking a more strategic approach in addressing the issues that affect them. And participation in ALAC had enabled participants to address the barriers that specific communities were facing more effectively too. These included examples such as participants helping to organise a local event for 500 women, with stalls providing information on health issues such as domestic violence and breast cancer and participants working together to find commonalities and connections, through helping Muslim women to overcome language barriers and isolation, and through promoting children's involvement in Month of Ramadan activities. Through this participatory method then the evaluators, facilitators and participants had the opportunity to work together to identify the wider impacts of ALAC and discuss and agree future ways of evidencing these impacts. 


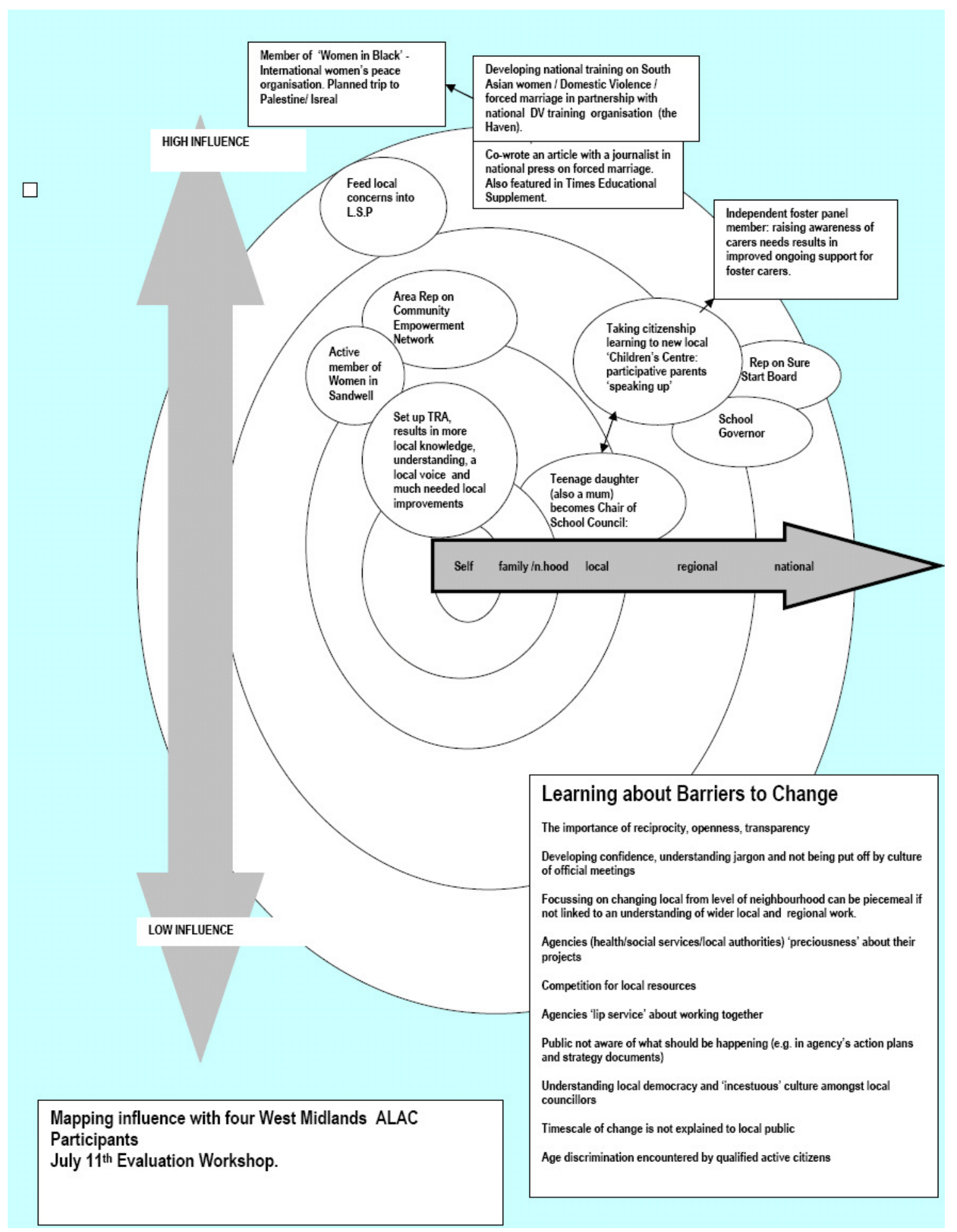

The Sheffield Workshop and the diagram from the 'individual' through to the 'international'. 


\section{Reflecting upon the lesson learned}

There was broad agreement that participatory approaches did indeed represent the most appropriate strategy for monitoring and evaluating the ALAC programme. And this was far more than a commitment to the use of particular participatory tool kits and tools, however useful these may be in themselves. There was genuine commitment to this, as part of a wider commitment to ALAC as an on-going process to promote empowerment and democratic social change. But there were challenges and limitations too.

Although the hubs and their participants shared reflections on how to use participative approaches to evaluate the wider ripple effects, for example, this issue was by no means resolved. Whilst ALAC did address issues that went beyond the confines of the local, linking the local with the national and the global, these wider impacts proved particularly challenging to track in the here and now, let alone for the future. And new initiatives were continuing to emerge, in any case, building upon the lessons from ALAC's initial experiences.

The impact on service delivery remains similarly challenging to track. Realistically, these arenas involve wider policy decisions. However exemplary the advocacy of active citizens, individually and collectively, policy makers may or may not be persuaded to redirect resources to meet their requests.

There are parallels questions to be addressed concerning sustainability more generally, too. Although the evaluation included so-called 'hard data' - facts and figures in response to bureaucratic requirements - this was, of course, no guarantee that successful initiatives would continue to obtain funding. The hubs have demonstrated resourcefulness and creativity in their efforts to secure sustainable futures for effective programmes. But there are major challenges for the future, given the pressures on funding more generally.

There would seem to be parallels here as well as contrasts with experiences of participative evaluation in the global South. As Kate Newman's article on the participatory evaluation of REFLECT illustrates, there are competing definitions and agendas to be taken into account. And whichever approach evaluators adopt, there are aspects of programmes that are genuinely problematic to evaluate, using participative approaches. Participation may - or may not - be experienced as genuinely empowering in any case: on the contrary, in fact, participants may feel increasingly alienated and disempowered if their voices remain unheard by policy makers and service providers.

Participatory evaluation raises challenges as well as opening up possibilities then, challenges and possibilities that emerged in both contexts, As Kate Newman concludes, no participatory evaluation will be perfect. But the final outcome is likely to be more honest and ultimately more fruitful, for the development of strategies to promote community empowerment and democratic social change for the longer term. 


\section{References}

Burns, D., Heywood, F., Wilde, P. and Wilson, M. (2004) What works in assessing community participation? (Bristol: Policy Press)

Cooke, B. and Kothari, U. (2001) 'The Case for Participation as Tyranny' in Cooke, B. and Kothari, U., eds. (2001) Participation: The New Tyranny? (London: Zed) 1-15

Cousins, J. B. and Whitmore, E. (1998) 'Framing Participatory Evaluation' in E. Whitmore, ed. (1998) Understanding and Practising Participatory Evaluation (San Franscisco: Jossey-Bass) 5-23

Institute of Development Studies (1998) Policy Briefing on Participatory Monitoring and Evaluation: Learning from Change (IDS, University of Sussex: Policy Briefing 12)

Mayo, M. and Rooke, A. (2006) Active Learning for Active Citizenship: An evaluation report

Mosse, D. (2001) '"People's Knowledge", Participation and Patronage: Operations and Representations in Rural Development' in Cooke, B. and Kothari, U., eds. (2001) Participation: The New Tyranny? (London: Zed) 16-35

Woodward, V. (2004) Active Learning for Active Citizenship (London: CRU, Home Office) 